\title{
Is pituitary MRI screening necessary in cluster headache?
}

\author{
Lou Grangeon 1,2,3, Emer O'Connor',2, Daisuke Danno',2, \\ Thanh Mai Pham Ngoc ${ }^{4}$, Sanjay Cheema ${ }^{1,2}$ (D), \\ Erling Tronvik ${ }^{5,6,7}$, Indran Davagnanam ${ }^{8}$ and \\ Manjit Matharu' ${ }^{1,2}$ (1)
}

(9SAGE

\begin{abstract}
Objective: To determine the prevalence and clinical predictors of pituitary adenomas in cluster headache patients, in order to determine the necessity of performing dedicated pituitary magnetic resonance imaging in patients with cluster headache.

Methods: A retrospective study was conducted of all consecutive patients diagnosed with cluster headache and with available brain magnetic resonance imaging between 2007 and 2017 in a tertiary headache center. Data including demographics, attack characteristics, response to treatments, results of neuroimaging, and routine pituitary function tests were recorded.

Results: Seven hundred and eighteen cluster headache patients attended the headache clinic; 643 underwent a standard magnetic resonance imaging scan, of whom 376 also underwent dedicated pituitary magnetic resonance imaging. Pituitary adenomas occurred in 17 of 376 patients (4.52\%). Non-functioning microadenomas $(n=14)$ were the most common abnormality reported. Two patients, one of whom lacked the symptoms of pituitary disease, required treatment for their pituitary lesion. No clinical predictors of those adenomas were identified after multivariate analysis using random forests. Systematic pituitary magnetic resonance imaging scanning did not benefit even a single patient in the entire cohort.

Conclusion: The prevalence of pituitary adenomas in cluster headache is similar to that reported in the general population, thereby precluding an over-representation of pituitary lesions in cluster headache. We conclude that the diagnostic assessment of cluster headache patients should not include specific pituitary screening. Only patients with standard brain magnetic resonance imaging findings or symptoms suggestive of a pituitary disorder require brain magnetic resonance imaging with dedicated pituitary views.
\end{abstract}

\section{Keywords}

Cluster headache, trigeminal autonomic cephalalgias, pituitary lesion, neuroimaging, pituitary MRI

Date received: 4 April 2020; revised: 19 October 2020; accepted: 19 November 2020

\section{Abbreviations \\ MRI: Magnetic resonance imaging \\ $\mathrm{CCH}$ : Chronic cluster headache \\ ECH: Episodic cluster headache}

\footnotetext{
'Headache and Facial Pain Group, UCL Queen Square Institute of Neurology, Queen Square, London, UK

${ }^{2}$ Headache and Facial Pain Group, The National Hospital for Neurology and Neurosurgery, Queen Square, London, UK

${ }^{3}$ Department of Neurology, Rouen University Hospital, Rouen, France

${ }^{4}$ Mathematics Institute of Orsay, Paris Sud University, Orsay, France

${ }^{5}$ Department of Neurology, St Olav's University Hospital, Trondheim, Norway
}

TAC: Trigeminal autonomic cephalalgia IHS: International Headache Society

\footnotetext{
${ }^{6}$ NTNU (University of Science and Technology), Department of Neuromedicine and Movement Science, Trondheim, Norway

${ }^{7}$ Norwegian Advisory Unit on Headaches, Trondheim, Norway ${ }^{8}$ Department of Brain Repair and Rehabilitation, UCL Queen Square Institute of Neurology, Queen Square, London, UK
}

Corresponding author:

MS Matharu, Headache and Facial Pain Group, UCL Queen Square Institute of Neurology; The National Hospital for Neurology and Neurosurgery, Queen Square, London WCIN 3BG, UK. Email: m.matharu@uclmail.net 
ICHD: International Classification of Headache Disorders

\section{Introduction}

Cluster headache $(\mathrm{CH})$ is a trigeminal autonomic cephalalgia (TAC) with a prevalence of $0.1-0.2 \%(1-3)$. It is often considered to be one of the most painful conditions known to mankind. While $\mathrm{CH}$ occurs as a primary headache syndrome in the vast majority of patients, it can be mimicked by symptomatic causes in a smallminority of patients. There are several reports in the literature suggesting that $\mathrm{CH}$ can be mimicked by pituitary disease (4-7).

Headache is a common presenting feature of pituitary disease, with a reported prevalence of $33-72 \%$ in patients with pituitary tumours $(8,9)$. A prospective study of 84 patients with pituitary tumours reported that $\mathrm{CH}$ occurred in $4 \%$, highlighting a possible overrepresentation of $\mathrm{CH}$ in this population (10). However, this study was conducted in a tertiary referral neurosurgical centre, and may reflect selection bias. Furthermore, other studies that investigated evidence for pituitary adenomas in $\mathrm{CH}$ were limited by the small number of patients included (4-6). It therefore remains unclear as to whether a higher prevalence of pituitary tumours exists in $\mathrm{CH}$ patients, as no large study with neuroimaging has been performed to address this issue. As a result, the requirement for pituitary imaging in $\mathrm{CH}$ patients remains a matter of debate.

A review by Cittadini and Matharu recommended an MRI of the pituitary in cases with atypical features, pituitary-related symptoms, abnormal neurological examination, or a poor response to treatment (6). Atypical features or "red flags" reported in the literature include an older age at onset, prolonged duration, higher frequency of attacks, bilateral or absence of autonomic symptoms $(4,11,12)$. In contrast, several national guidelines, including the French headache society and Scottish Intercollegiate Guidelines Network (SIGN) guidelines recommend performing MRI with dedicated pituitary views in all $\mathrm{CH}$ patients $(13,14)$. This approach may result in $\mathrm{CH}$ being erroneously attributed to an incidental lesion of no significance. As incidental pituitary lesions are found on routine MRI in approximately $10 \%$ of the general population, this risk is considerable (15-17).

In order to determine the necessity of performing a dedicated pituitary MRI in $\mathrm{CH}$, the aim of this study was to assess the prevalence of pituitary adenomas in $\mathrm{CH}$ patients and attempt to identify clinical predictors of pituitary adenomas in $\mathrm{CH}$ patients.

\section{Material and methods}

\section{Patients}

A retrospective study was conducted in the Headache clinic at the National Hospital for Neurology and Neurosurgery (Queen Square, London, UK). All consecutive patients who attended the headache clinic between January 2007 and April 2017, diagnosed with episodic cluster headache $(\mathrm{ECH})$ or chronic cluster headache $(\mathrm{CCH})$ according to the International Classification of Headache Disorders 3rd edition (ICHD-3) diagnostic criteria, were included (1). Two independent neurologists established a diagnosis of probable $\mathrm{CH}$ in case where one of the ICHD-3 criteria was not met. Cases in whom the clinical presentation overlapped with paroxysmal hemicrania and an optimum indomethacin trial had not been performed or was contraindicated were defined as probable TAC and were excluded from this study.

The data collected included demographics, diagnosis, laterality, site and quality of pain, attack characteristics (frequency, duration, and severity), associated symptoms (including autonomic and migrainous features) and concurrent headache syndromes. In addition, each patient had undergone a comprehensive clinical examination focusing on pituitary disorder

Table I. Definitions of intractable response to treatments (modified from European Headache Federation consensus guideline and Goadsby et al.) (2,3).

Adequate trial performed

Appropriate dose: Decision left to the clinical physician

Appropriate length of time:

At least I month for melatonin trial

At least 3 months for all other preventive therapeutics

Failed trial

Unsatisfactory response:

Less than $50 \%$ reduction in mean attack frequency for preventive treatment

Less than $50 \%$ reduction in pain at least $50 \%$ of the time for acute treatment

Side-effects requiring cessation of treatment

Contraindications to use

Intractable to acute treatment:

Failure to respond within 15 min of subcutaneous sumatriptan use and

Failure within $30 \mathrm{~min}$ of high dose and flow rate oxygen use Intractable to preventive treatment:

Failure of at least four classes among Verapamil

Lithium

Topiramate

Gabapentin

Methysergide

Melatonin 
symptoms such as menstruation changes, galactorrhoea, hirsutism, erectile dysfunction or acromegaly; data on this pituitary evaluation was collected.

In order to evaluate the response to acute and preventive treatments, we used a modified definition of intractable $\mathrm{CH}$ based on the consensus statements and expert opinions published in the literature (see Table 1) $(18,19)$. A satisfactory response to a trial was defined as a $50 \%$ or more reduction in mean attack frequency for preventive medication and a $50 \%$ or more reduction in pain at least $50 \%$ of the time for acute medication (20).

All participants gave informed consent and ethics board approval was obtained from The National Hospital for Neurology and Neurosurgery Research Ethics Committee, London, UK (REC number: 07/Q0512/26).

\section{Neuroimaging and pituitary assessment}

All routine MRI brain or MRI with dedicated pituitary views were performed on either a 1.5 (Siemens Avanto, Ernlagen) or 3 Tesla (Siemens Trio, Ernlagen) scanner. The pituitary MRI protocol included $3 \mathrm{~mm}$ thick T1- and T2-weighted coronal and sagittal sections centred on the sellar region. If a pituitary lesion was clearly observed on the pre-contrast imaging, additional coronal and sagittal high-resolution $3 \mathrm{~mm}$ sequences were then performed (21). Microadenoma $(<10 \mathrm{~mm})$ or macroadenoma $(>10 \mathrm{~mm})$ were classified according to the maximal tumour diameter (22). A primary empty sella or arachnoidocele was defined as the herniation of the subarachnoid space within the sella turcica. Empty sella was classified as partial when less than $50 \%$ of the sella was filled with cerebrospinal fluid $(23,24)$. Regarding cystic formations, they were categorised as Rathke's cleft cyst, pars intermedia cyst or as anterior pituitary cyst.

Routine pituitary function tests were assessed in line with the standard practice in most headache centres in the UK. The blood tests performed included prolactin, growth hormone, insulin-like growth factor type 1, random cortisol, thyroxine (T4), thyroid stimulating hormone, random cortisol, testosterone, follicle stimulating hormone, luteinising hormone, oestrogen and progesterone.

In order to accurately assess the prevalence of pituitary adenomas, we only included patients who underwent MRI with dedicated pituitary views. To identify the clinical predictors of pituitary adenomas, we divided the cohort into two groups, those with or without a pituitary adenoma.

\section{Statistics}

Descriptive statistics were expressed as mean with standard deviation (SD) and median. Missing data were not replaced by imputation techniques. The two groups of patients were compared using a MannWhitney nonparametric test for quantitative data and a Fisher's exact or chi-square test for qualitative data. The threshold for statistical significance was set to $p \leq 0.05$. For multivariate analysis, random forests were used.

Random forests, introduced by Breiman, is a very popular and efficient general-purpose approach for classification and regression (25). The principle of random forests combines a multitude of binary randomised decision trees and aggregates their predictions by averaging.

In this study, after having split our genuine dataset into training and test sets, we used the $\mathrm{R}$ package VSURF based on random forests to perform variable selection (26). Variable selection is a crucial issue in classification problems to remove irrelevant explanatory variables. To perform variable selection, VSURF ranked the explanatory variables according to the variable importance (VI) criterion in the random forest framework. At the end of the ranking phase, a threshold was computed. Only variables with VI exceeding this threshold were retained for the interpretation and prediction steps.

Given the small number of pituitary adenomas compared to normal imaging, we resorted to weighted random forests to address the imbalanced dataset. A well-known and usual approach to face this problem and improve the prediction accuracy of the rare examples is to put a larger weight to the minority class. The $\mathrm{R}$ software was used to conduct our multivariate analysis.

\section{Data availability statement}

De-identified database and statistical analysis plan will be shared upon reasonable request for two years after publication.

\section{Results}

\section{Demographics}

A total of 718 patients were included in our study, of whom 504 were male $(70.2 \%)$. The mean age was 49.9 years (SD 12.3) and the mean age at $\mathrm{CH}$ onset was 31.4 years old (SD 13.0). The mean follow-up time in our headache clinic was 7.4 years (SD 3.9). 


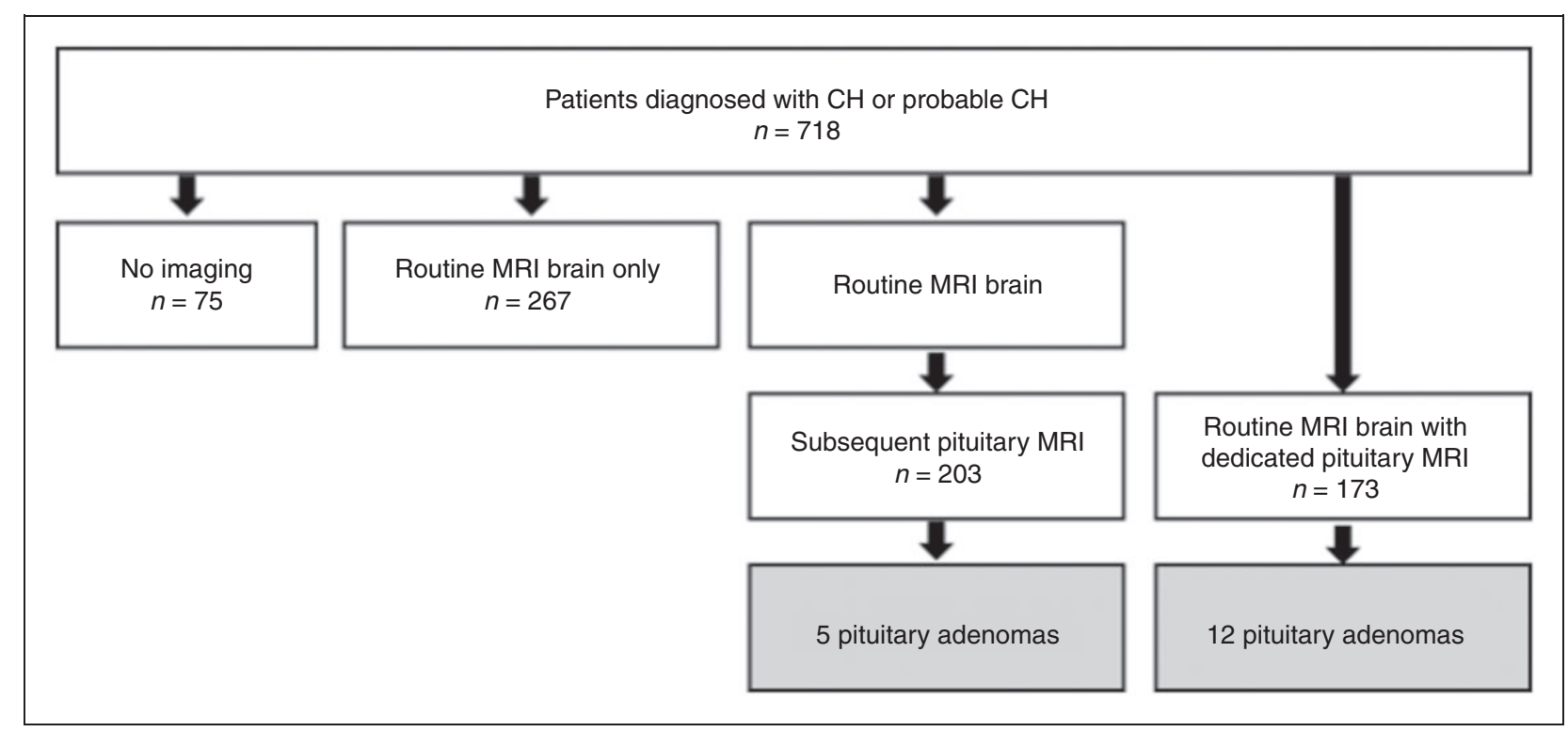

Figure I. Flow diagram showing patient disposition throughout the trial.

Table 2. Comparison between cluster headache patients who underwent routine MRI brain only versus routine MRI brain with dedicated pituitary views.

\begin{tabular}{|c|c|c|c|}
\hline & $\begin{array}{l}\text { Routine MRI brain only } \\
(n=267)\end{array}$ & $\begin{array}{l}\text { Routine MRI brain with dedicated pituitary views } \\
(n=376)\end{array}$ & $p$-value \\
\hline Age (years) & $51.9 \pm 12.5 ; 50(22-89)$ & $48.2 \pm$ II.8; 48 (22-78) & $<0.001$ \\
\hline Age at onset (years) & $31.3 \pm 14.4 ; 29(5-81)$ & $31.7 \pm 12.2 ; 30(10-72)$ & 0.34 \\
\hline Male & $188(69.6 \%)$ & $26 \mid(70.0 \%)$ & 0.93 \\
\hline Female & $82(30.3 \%)$ & $112(30.0 \%)$ & 0.93 \\
\hline $\mathrm{CH}$ duration (years) & $20.7 \pm 11.5 ; 18(0-64)$ & $16.5 \pm 10.2 ; 14(0-53)$ & $<0.001$ \\
\hline $\mathrm{ECH}$ & 119 (44.1\%) & $136(36.5 \%)$ & 0.07 \\
\hline $\mathrm{CCH}$ & $123(45.5 \%)$ & $198(53.0 \%)$ & 0.07 \\
\hline $\mathrm{PECH}$ & II (4.1\%) & $16(4.3 \%)$ & 1.00 \\
\hline $\mathrm{PCCH}$ & $17(6.2 \%)$ & $23(6.2 \%)$ & 1.00 \\
\hline
\end{tabular}

Note: Mean \pm standard deviation, median (minimum-maximum) for quantitative data, $\mathrm{n}(\%)$ for qualitative data.

$\mathrm{ECH}$ : episodic cluster headache; $\mathrm{CCH}$ : chronic cluster headache; $\mathrm{PECH}$ : probable episodic cluster headache; $\mathrm{PCCH}$ : probable chronic cluster headache.

\section{Imaging assessment}

Routine MRI brain alone was performed in 267 patients while 376 patients underwent a routine MRI brain along with dedicated pituitary views (see Figure 1). Seventy-five patients did not undergo any neuro-imaging and were lost to follow-up. Consistent with recent literature and guidelines, the utilisation of pituitary MRI has greatly increased over the last decade at our centre. From 2011 onwards, the majority of $\mathrm{CH}$ patients underwent routine MRI brain with dedicated pituitary views or had complementary pituitary sequences if a routine MRI brain had already been performed. No significant differences were found between the patients who underwent routine MRI and those who received pituitary MRI in terms of gender, age of onset or diagnosis (see Table 2).
Reflecting the recent neuro-imaging trends in the investigation of $\mathrm{CH}$, younger patients $(48.2 \pm 11.8$ years vs. $51.9 \pm 12.5$ years, $p<0.001)$ and those with a shorter history of $\mathrm{CH}(16.5 \pm 10.2$ years vs. $20.7 \pm 11.5$ years, $p<0.001)$ were more likely to undergo a dedicated pituitary MRI. Finally, only $41(5.7 \%)$ patients had already had a pituitary MRI prior to attending our headache clinic.

\section{Radiological pituitary abnormalities}

Of the 376 patients in whom dedicated pituitary MRI had been performed, $35(9.3 \%)$ had a pituitary abnormality. Details regarding the pituitary abnormalities found are presented in Table 3 . Of the 35 pituitary abnormalities, 17 were diagnosed with adenomas. Non-functioning microadenoma $(n=14)$ were the 
Table 3. Pituitary lesions identified in cohort.

\begin{tabular}{|c|c|c|c|c|c|c|}
\hline $\begin{array}{l}\text { Nature of lesion } \\
\text { Total }=35\end{array}$ & & Number & $\begin{array}{l}\text { Detected on } \\
\text { routine MRI first }\end{array}$ & $\begin{array}{l}\text { Pituitary } \\
\text { related } \\
\text { symptoms }\end{array}$ & $\begin{array}{l}\text { Specific } \\
\text { medical } \\
\text { treatment }\end{array}$ & $\begin{array}{l}\text { Surgical } \\
\text { treatment } \\
\text { offered }\end{array}$ \\
\hline \multirow[t]{3}{*}{ Micro adenoma $(n=16)$} & Functioning & 1 & 1 & 1 & 1 & 0 \\
\hline & Non-functioning & 14 & 2 & 0 & 0 & 0 \\
\hline & Data not available & 1 & 0 & 1 & DNA & DNA \\
\hline Macro adenoma $(n=1)$ & Functioning & 1 & 0 & 0 & 1 & 0 \\
\hline Pituitary haemorrhage $(n=1)$ & & I & 1 & 0 & 0 & 0 \\
\hline \multirow[t]{2}{*}{ Empty sella $(\mathrm{n}=8)$} & Partially & 6 & 0 & 0 & 0 & 0 \\
\hline & Fully & 2 & 2 & 0 & 0 & 0 \\
\hline Rathke's cleft cyst $(n=5)$ & & 5 & 0 & 0 & 0 & 0 \\
\hline \multirow{2}{*}{ Other cystic formation $(n=4)$} & Anterior pituitary cyst & 1 & 0 & 0 & 0 & 0 \\
\hline & Pars Intermedia cyst & 3 & 0 & 0 & 0 & 0 \\
\hline
\end{tabular}

DNA: Data not available.

most common abnormality, followed by empty sella syndrome $(n=8)$, Rathke's cleft cyst $(n=5)$, other cystic formations $(n=4)$, functioning microadenoma $(\mathrm{n}=1)$, functioning macroadenoma $(\mathrm{n}=1)$ and spontaneous pituitary haemorrhage $(n=1)$. One patient had a microadenoma, but it had not been ascertained whether it was functioning or non-functioning.

The two functioning adenomas were prolactinomas. The patient with macroprolactinoma presented with a 3 -year history of $\mathrm{CH}$ but no pituitary symptoms. The other patient had galactorrhoea secondary to a microprolactinoma, which has been diagnosed 23 years after the first $\mathrm{CH}$ attack. In terms of treatment, the two prolactinomas were treated with dopamine agonists but did not require surgery. Treatment led to a partial improvement of the $\mathrm{CH}$ attacks in the patient with a macroprolactinoma but had no impact in the patient with the microprolactinoma.

Two patients had pituitary symptoms. Besides the patient who presented with galactorrhoea secondary to a microprolactinoma that was diagnosed 23 years after the first $\mathrm{CH}$ attack, another patient had menstruation changes and hirsutism with a pituitary microadenoma, in whom pituitary blood profile was not available and who was lost to follow-up despite several attempts to contact her.

Of note, one patient with a microadenoma showed a slightly elevated IGF-1 level but with normal GH level and no signs of acromegaly; on prolonged follow up of 9 years, the microadenoma remained unchanged on serial MRI scans and the IGF-1 level fluctuated between being slightly elevated or normal with normal GH levels. This patient was deemed to have non-functioning microadenoma.

Notably, in the 203 patients who had a routine MRI followed by a subsequent pituitary MRI, 10 additional pituitary lesions were detected, including five pituitary microadenomas, but none required any specific treatment.

\section{Routine pituitary blood profile}

Of the 718 patients, $342(47.6 \%)$ underwent a pituitary function profile at our centre. For the remaining 376 patients $(52.4 \%)$, the primary care physicians were advised to perform these investigations. The results of the routine pituitary blood profile performed in primary care were not available. Of the patients with a pituitary abnormality, $28(80.0 \%)$ profiles were available. In addition, the results of $254(72.3 \%)$ patients with normal pituitary imaging were also reviewed. Minor abnormalities, with slightly low or elevated levels which were not considered to be clinically significant, were found in 71 patients with normal pituitary imaging $(27.9 \%)$ and in eight patients with a pituitary lesion $(28.5 \%)$. This was not statistically significant $(p=0.64)$.

Only two significant blood test abnormalities were found in the cohort. This included an increased prolactin $(8806 \mathrm{mIU} / \mathrm{L}$ for macro-adenoma and $2003 \mathrm{mIU} / \mathrm{L}$ for micro-adenoma respectively) in two patients. The macroprolactinoma was discovered on MRI after the first headache clinic of the patient. The patient had presented with a 3-year history of $\mathrm{CH}$, the majority of which were left sided $(97 \%)$. The pituitary adenoma was described as almost completely replacing normal tissue in the left and central aspects of the sella, with a sliver of normal pituitary tissue located in the right aspect of the fossa (see Figure 2). There was no suprasellar extension and the pituitary stalk was deviated slightly to the right. The macro-prolactinoma did not generate any pituitary symptoms. The volume decreased after cabergoline but the $\mathrm{CH}$ only partially 


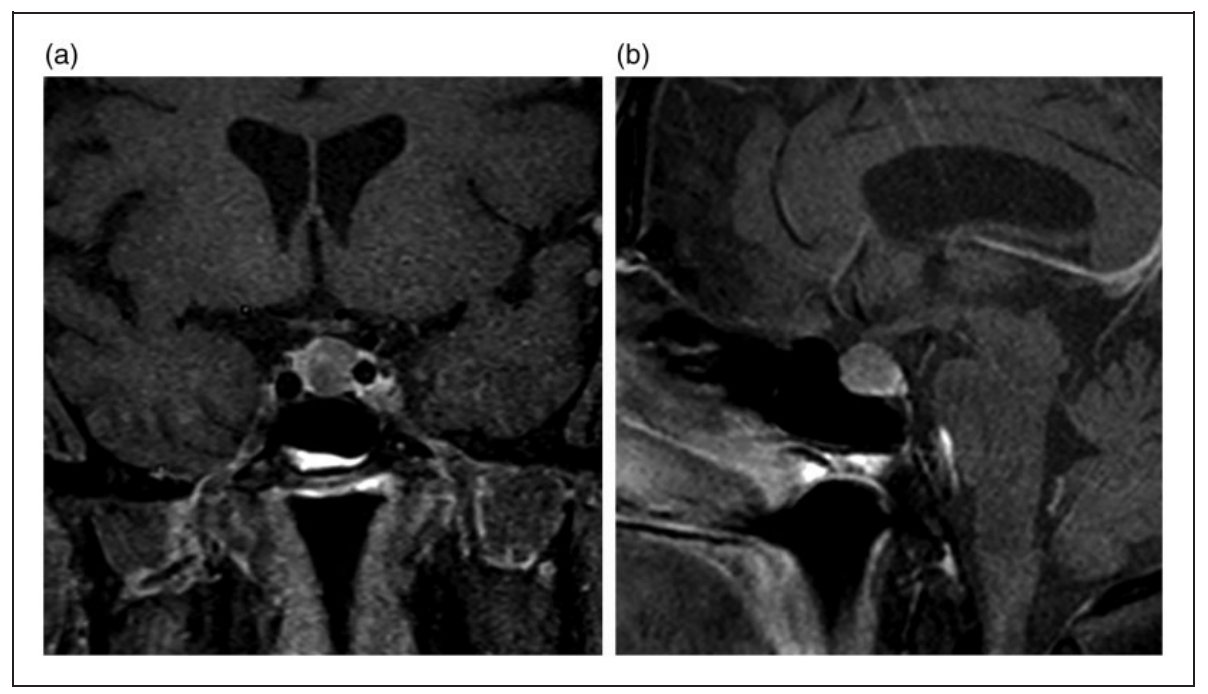

Figure 2: Coronal (a) and sagittal (b) sections of the MRI scan of a cluster headache patient with a macroprolactinoma.

improved and he therefore required ongoing management of his $\mathrm{CH}$.

\section{Comparison between patients with pituitary adenomas and patients with normal pituitary imaging}

In order to identify clinical predictors of an underlying pituitary lesion in patients with $\mathrm{CH}$, we compared patients with a pituitary adenoma $(n=17)$ to those without $(n=359)$. Univariate analyses were performed and are summarised in Table 4 . The only significant item was the nasal location $(p=0.04)$. No other statistical difference was found in terms of demographics, laterality, and frequency of $\mathrm{CH}$ attacks or associated features. Regarding the response to medical treatment, no difference was found between the patients with pituitary adenomas and those with normal imaging in terms of response to acute and/or preventive treatment ( $p=1$ and $p=0.47$ respectively).

Multivariate analysis using the VSURF algorithm was used to further assess these univariate results. First, we split our dataset into a training set and a test set with respectively $80 \%$ and $20 \%$ of the genuine dataset. The training set included 14 patients with a pituitary adenoma and 288 patients without. In the training set, 65 patients with at least one missing value were detected. Thus, we imputed missing values with the rfImpute function based on random forests (the rfImpute function of the $\mathrm{R}$ software). To reflect the data imbalance proportion, we put a weight of 20 on patients with pituitary adenoma and a weight of 1 on patients without pituitary adenoma. Next, we launched VSURF to perform variable selection and determine a sufficient subset of variables for prediction. VSURF did not select any variables at the prediction step. Thus, we concluded that no variables were actually relevant as clinical predictors of pituitary adenoma.

\section{Discussion}

Here we report that, in a large cohort of $\mathrm{CH}$ patients, pituitary adenomas occurred in $4.5 \%$ of cases. This is in keeping with the estimated prevalence of pituitary adenomas in the general population, which ranges from $1.5 \%$ to $31 \%$, with an average prevalence of $10.6 \%$ $(25,26)$. With the widespread use of imaging techniques, such lesions are now identified regularly (26). Consistent with this, the largest autopsy series of 178 pituitary glands found incidental lesions in 34\% of cases (15). Furthermore, a meta-analysis of autopsy and imaging studies reported pituitary adenomas in $16.7 \%$ of the general population (16). Our study showed that there was no over-representation of pituitary adenomas in our cohort of $\mathrm{CH}$ patients.

Macroadenomas or functioning microadenomas have previously been implicated in $\mathrm{CH}(6,8,27)$. The pathophysiological mechanism of this is poorly understood. Classically, these headaches were attributed to stretching of the dura mater in the presence of a suprasellar extension or invasion of the cavernous sinus, causing direct irritation of the trigeminal nerve $(6,12)$. A lack of association of tumour size with headache deviates from this hypothesis $(8,28,29)$. Biochemical disturbances and the secretion of a "nociceptive peptide" by pituitary adenomas have also been suggested $(9,30)$.

Our study sought to determine the usefulness of MRI with dedicated pituitary views in $\mathrm{CH}$ diagnosis assessment, without denying the usefulness of a routine 
Table 4. Univariate analysis results of comparison between patients with pituitary adenoma and patients with normal neuroimaging.

\begin{tabular}{|c|c|c|c|}
\hline & $\begin{array}{l}\text { No pituitary adenoma } \\
(\mathrm{n}=359)\end{array}$ & $\begin{array}{l}\text { Pituitary adenoma } \\
(n=17)\end{array}$ & $p$-value \\
\hline \multicolumn{4}{|l|}{ Demographics and diagnosis } \\
\hline Age (years old) & $48.05 \pm 11.85$ & $49.11 \pm 10.67$ & 0.89 \\
\hline Age at onset (years old) & $31.64 \pm 12.17$ & $28.88 \pm 12.5$ & 0.44 \\
\hline \multicolumn{4}{|l|}{ Sex } \\
\hline Male & $252(70.1 \%)$ & $10(58.8 \%)$ & 0.46 \\
\hline Female & 107 (29.8\%) & $7(4 \mid .2 \%)$ & 0.46 \\
\hline \multicolumn{4}{|l|}{ Diagnosis } \\
\hline $\mathrm{ECH}$ & $126(36.9 \%)$ & $12(34.3 \%)$ & 0.76 \\
\hline $\mathrm{CCH}$ & 178 (52.1\%) & $21(60.0 \%)$ & 1.00 \\
\hline Probable $\mathrm{CH}$ & 37 (10.8\%) & $2(5.7 \%)$ & 0.52 \\
\hline Headache duration & $16.27 \pm 9.84$ & $20.23 \pm 15.85$ & 0.51 \\
\hline \multicolumn{4}{|l|}{ Duration, frequency of attacks } \\
\hline Duration of attack & $103.9 \pm 162.39$ & $103.23 \pm 58.33$ & 0.43 \\
\hline Frequency & $2.99 \pm 2.12$ & $2.76 \pm 1.34$ & 0.86 \\
\hline \multicolumn{4}{|l|}{ Laterality } \\
\hline Strictly unilateral & $292(82.49 \%)$ & $12(70.6 \%)$ & 0.21 \\
\hline Side-variable & $58(17.0 \%)$ & $4(23.5 \%)$ & 0.55 \\
\hline Bilateral & $9(2.5 \%)$ & I (5.9\%) & 0.37 \\
\hline \multicolumn{4}{|l|}{ Site } \\
\hline Orbital/retro-orbital & 241 & 26 & 0.78 \\
\hline Nasal & 25 & 4 & $0.04 *$ \\
\hline Frontal & 122 & 6 & 1.00 \\
\hline Temple & 161 & 15 & 0.08 \\
\hline Parietal & 54 & 7 & 1.00 \\
\hline Vertex & 42 & 5 & 0.24 \\
\hline Occiput & 75 & 7 & 0.77 \\
\hline \multicolumn{4}{|c|}{ Cranial autonomic features and restlessness } \\
\hline Ptosis & 210 & 17 & 0.66 \\
\hline Eye oedema & 130 & 13 & 0.30 \\
\hline Conjunctival injection & 257 & II & 0.55 \\
\hline Miosis & 10 & 3 & 0.45 \\
\hline Lacrimation & 279 & 27 & 0.44 \\
\hline Nasal blockage & 203 & 24 & 0.23 \\
\hline Rhinorrhea & 213 & 20 & 0.29 \\
\hline Sweating & 180 & 17 & 0.78 \\
\hline Facial flush & 143 & 16 & 0.25 \\
\hline Aural fullness & 73 & 5 & 1.00 \\
\hline Restlessness & $283(82.9 \%)$ & $30(85.7 \%)$ & 0.23 \\
\hline \multicolumn{4}{|l|}{ Response to medical treatment } \\
\hline Intractable to acute treatment & 14 (4.33\%) & 0 & 1.00 \\
\hline Intractable to preventive treatment & $84(32 \%)$ & $5(45.4 \%)$ & 0.47 \\
\hline
\end{tabular}

Note: Mean \pm standard deviation for quantitative data, $\mathrm{n}(\%)$ for qualitative data.

$\mathrm{ECH}$ : episodic cluster headache; $\mathrm{CCH}$ : chronic cluster headache; $\mathrm{CH}$ : cluster headache.

*Nasal location of pain was the only statistically significant factor on univariate analysis

brain MRI. Of the 376 patients who underwent MRI with dedicated pituitary views, two patients with prolactinomas required specific medical treatment for their pituitary lesion. However, only one patient lacked the symptoms of pituitary disease and therefore risked remaining undiagnosed. However, this patient had a pituitary macroadenoma that was clearly visible on routine brain MRI and would have been detected without the need for a dedicated pituitary MRI. Thus, the dedicated pituitary MRI did not benefit even a single patient in the entire cohort.

Our findings also challenge the usefulness of routine pituitary function tests in $\mathrm{CH}$ patients. Indeed, merely two significant abnormalities (including one in a symptomatic patient) were identified out of the 342 sets of tests performed. Additionally, "minor abnormalities", 
of no clinical relevance, were reported in equal proportion in patients with and without pituitary adenomas. This suggests that, in the setting of a normal brain MRI, pituitary blood tests are not helpful.

Given that our dataset was very imbalanced with only $4.5 \%$ of cases having a pituitary adenoma, the univariate analyses could not be considered reliable. We thus used a robust statistical approach, based on 50 runs of weighted random forests. Interestingly, no clinical characteristic or atypical headache feature could be identified as predictive of a pituitary adenoma, contradicting the common belief that patients with pituitary lesions present atypically and are less responsive to treatment.

Interpreting the significance of pituitary lesions found in cluster headache patients is problematic. According to the ICHD-3 criteria for "headache attributed to pituitary hyper- or hypo-secretion", evidence of causation includes a temporal relation to the onset of pituitary dysfunction and headache, and/or improvement with treatment of the pituitary lesion (1). None of the patients with pituitary adenomas in our cohort, including those with functioning lesions $(n=2)$, fulfilled these criteria. According to Levy and colleagues, only $49 \%$ of patients reported an improvement in their headaches following surgical intervention for a pituitary tumour (10). In our study, $\mathrm{CH}$ attacks persisted in patients with prolactinomas following treatment with dopamine agonists. While this does not mean that pituitary lesions cannot be involved in the $\mathrm{CH}$ genesis, our study suggests that the vast majority of pituitary lesions in $\mathrm{CH}$ are incidental lesions whose discovery will neither impact on the $\mathrm{CH}$ management nor modify the endocrinological management. In view of this, headache alone remains a controversial indication for the treatment of pituitary tumours $(29,31)$. In this respect, we note that unremitting headache is also listed as a relative indication for surgery in guidelines established by the Endocrine Society of Colombia (32). Additionally, the lack of robust guidelines for the management of non-functioning lesions which, when invasive, may potentially mimic $\mathrm{CH}$, further complicates this clinical conundrum (33).

The issue of pituitary lesions in $\mathrm{CH}$ is akin to that of vascular lesions. As with pituitary adenomas, there are several reports of carotid dissection or aneurysms in association with $\mathrm{CH}(7,34-36)$. It could be argued that MR angiography is of as equivocal diagnostic value as pituitary MRI in this group of patients. The risk with specifically scanning all patients for pituitary abnormalities (or vascular lesions) in addition to routine brain MRI is that the diagnostic yield is very low, while the chances of identifying an incidental lesion is relatively high. Furthermore, the cost effectiveness of this diagnostic strategy is very poor.
This poses the question as to whether pituitary lesions can indeed lead to the onset of TACs, in particular $\mathrm{CH}$. There are numerous case reports in the literature that suggest that TACs can arise from pituitary lesions $(6,10)$. While these case reports and case series clearly point towards some cases of TACs arising from pituitary lesions, our study suggests that this is a rare cause of secondary $\mathrm{CH}$. Though this is a rare entity, we nonetheless recognise that it exists and needs to be recognised and sought by both headache specialists and endocrinologists. Further studies are needed to ascertain the differences in clinical presentation of the patients with $\mathrm{CH}$ secondary to pituitary lesions versus primary $\mathrm{CH}$ before any recommendations can be made about which patients need to be investigated further with dedicated pituitary imaging and blood tests.

To our knowledge, this is the largest study of pituitary imaging in a $\mathrm{CH}$ cohort from a tertiary clinicbased population. Though our cohort has the same sex ratio and age of onset as other $\mathrm{CH}$ series, the higher proportion of $\mathrm{CCH}(50 \%)$ is reflective of the fact that the study was conducted in a tertiary referral centre (3). Despite this, only $5.7 \%$ of our cohort had undergone pituitary MRI prior to attending our headache clinic, precluding a referral bias in terms of pituitary screening. However, replication of our findings in a secondary care setting is required.

Other weaknesses of this study include its retrospective nature and lack of MRI with dedicated pituitary view in all patients. However, it is most unlikely that the incidence of pituitary lesions would change in prospective series. Furthermore, pituitary hormone profile results were only available in 342 of 718 patients $(47.6 \%)$, albeit that the focus of the study was to assess the utility of performing dedicated pituitary MRI scans rather than the blood tests.

In conclusion, we demonstrated that pituitary adenomas do not occur at a higher frequency in $\mathrm{CH}$ patients compared to the general population. Furthermore, there were no clinical predictive factors that distinguish $\mathrm{CH}$ patients with adenomas from primary $\mathrm{CH}$, which is in keeping with the notion that most pituitary adenomas are an incidental finding and not the cause of the headache. Therefore, we suggest that the diagnostic assessment of $\mathrm{CH}$ patients should not routinely include additional specific pituitary screening with dedicated MRI pituitary scans. It should be carried out if there are symptoms or features on standard brain MRI that are suggestive of pituitary disease. Given the low incidence of pituitary lesions in $\mathrm{CH}$ patients, this recommendation would not only improve cost-effectiveness but would also provide a more targeted diagnostic evaluation. 


\section{Clinical implications}

- Incidence of pituitary adenomas in cluster headache is similar to that reported in the general population.

- No clinical predictors of pituitary adenomas were identified.

- The diagnostic assessment of cluster headache should not include specific pituitary screening.

- Only patients with standard brain MRI findings or symptoms suggestive of a pituitary disorder require brain MRI with dedicated pituitary views.

\section{Acknowledgements}

We would like to thank our Headache Specialist Nurses for their help with completion of the clinical database and management of the patients. We also thank the patients and their families for their help with this project.

\section{Author contributions}

LG: Collection, analysis and interpretation of data, drafting and revision of manuscript.

EO: Analysis and interpretation of data, drafting and revision of manuscript.

DD: Collection and analysis of data.

TP: Statistical analysis and interpretation of data, drafting of manuscript.

SC: Interpretation and analysis of data, manuscript revision.

ET: Interpretation of data and manuscript revision.

ID: Analysis and interpretation of data, manuscript revision. MSM: Study concept, recruitment of subjects, interpretation of data and manuscript revision.

\section{Declaration of conflicting interests}

The authors declared the following potential conflicts of interest with respect to the research, authorship, and/or publication of this article: LG, EO, DD, TP, SC, ET and ID report no disclosures. MSM serves on the advisory board for Abbott, Allergan, Eli Lilly, Medtronic, Novartis and TEVA and has received payment for the development of educational presentations from Allergan, electroCore, Eli Lilly, Novartis and TEVA.

\section{Funding}

The authors received no financial support for the research, authorship, and/or publication of this article.

\section{ORCID iDs}

Sanjay Cheema (D) https://orcid.org/0000-0002-5438-6549

Manjit Matharu (D) https://orcid.org/0000-0002-4960-2294

\section{References}

1. Headache Classification Subcommittee of The International Headache Society. The International Classification of Headache Disorders 3rd edition (beta version). Cephalalgia 2013; 33: 629-808.

2. Lambru G and Matharu MS. Trigeminal autonomic cephalalgias: A review of recent diagnostic, therapeutic and pathophysiological developments. Ann Ind Acad Neurol 2012; 15: S51-S61.

3. Russell MB. Epidemiology and genetics of cluster headache. Lancet Neurol 2004; 3: 279-283.

4. Favier I, van Vliet JA, Roon KI, et al. Trigeminal autonomic cephalgias due to structural lesions: A review of 31 cases. Arch Neurol 2007; 64: 25-31.

5. de Coo IF, Wilbrink LA and Haan J. Symptomatic trigeminal autonomic cephalalgias. Curr Pain Headache Rep 2015; 19: 39.

6. Cittadini E and Matharu MS. Symptomatic trigeminal autonomic cephalalgias. Neurologist 2009; 15: 305-312.

7. Edvardsson B. Symptomatic cluster headache: A review of 63 cases. SpringerPlus 2014; 3: 64.

8. Abe T, Matsumoto K, Kuwazawa J, et al. Headache associated with pituitary adenomas. Headache 1998; 38: $782-786$.

9. Levy MJ, Matharu M and Goadsby PJ. Chronic headache and pituitary tumors. Curr Pain Headache Rep 2008; 12: 74-78.

10. Levy MJ, Matharu MS, Meeran K, et al. The clinical characteristics of headache in patients with pituitary tumours. Brain 2005; 128: 1921-1930.

11. Favier I, Haan J and Ferrari MD. Cluster headache: To scan or not to scan. Curr Pain Headache Rep 2008; 12: 128-131.

12. Mainardi F, Trucco M, Maggioni F, et al. Cluster-like headache. A comprehensive reappraisal. Cephalalgia 2010; 30: 399-412.

13. Donnet A, Demarquay G, Ducros A, et al. French guidelines for diagnosis and treatment of cluster headache (French Headache Society). Rev Neurol 2014; 170: 653-670.

14. Scottish Intercollegiate Guidelines Network (SIGN). Diagnosis and management of headache in adults (Guideline No 107). Edinburgh, November 2008, https:// www.headacheacademy.com/wp-content/uploads/2018/ 10/HG-SIGN-Headache-Full-Guideline.pdf (accessed 24 December 2020).

15. Teramoto A, Hirakawa K, Sanno N, et al. Incidental pituitary lesions in 1,000 unselected autopsy specimens. Radiology 1994; 193: 161-164.

16. Ezzat S, Asa SL, Couldwell WT, et al. The prevalence of pituitary adenomas: A systematic review. Cancer 2004; 101: 613-619.

17. Orija IB, Weil RJ and Hamrahian AH. Pituitary incidentaloma. Best Pract Res Clin Endocrinol Metab 2012; 26: 47-68. 
18. Goadsby PJ, Schoenen J, Ferrari MD, et al. Towards a definition of intractable headache for use in clinical practice and trials. Cephalalgia 2006; 26: 1168-1170.

19. Mitsikostas DD, Edvinsson L, Jensen RH, et al. Refractory chronic cluster headache: A consensus statement on clinical definition from the European Headache Federation. J Headache Pain 2014; 15: 79.

20. Schurks M, Kurth T, de Jesus J, et al. Cluster headache: Clinical presentation, lifestyle features, and medical treatment. Headache 2006; 46: 1246-1254.

21. Paschou SA, Vryonidou A and Goulis DG. Pituitary incidentalomas: A guide to assessment, treatment and follow-up. Maturitas 2016; 92: 143-149.

22. Cottier JP, Destrieux C, Brunereau L, et al. Cavernous sinus invasion by pituitary adenoma: MR imaging. Radiology 2000; 215: 463-469.

23. Guitelman M, Garcia Basavilbaso N, Vitale M, et al. Primary empty sella (PES): A review of 175 cases. Pituitary 2013; 16: 270-274.

24. De Marinis L, Bonadonna S, Bianchi A, et al. Primary empty sella. J Clin Endocrinol Metab 2005; 90: 5471-5477.

25. Molitch ME. Nonfunctioning pituitary tumors and pituitary incidentalomas. Endocrinol Metab Clin North Am 2008; 37: 151-171, xi.

26. Vassiliadi DA and Tsagarakis S. Endocrine incidentalomas - challenges imposed by incidentally discovered lesions. Nat Rev Endocrinol 2011; 7: 668-680.

27. Bussone G, Usai S and Moschiano F. How to investigate and treat: Headache and hyperprolactinemia. Curr Pain Headache Rep 2012; 16: 365-370.
28. Levy MJ, Jager HR, Powell M, et al. Pituitary volume and headache: Size is not everything. Arch Neurol 2004; 61: 721-725.

29. Siegel S, Weber Carneiro R, Buchfelder M, et al. Presence of headache and headache types in patients with tumors of the sellar region - can surgery solve the problem? Results of a prospective single center study. Endocrine 2017; 56: 325-335.

30. Levy MJ, Bejon P, Barakat M, et al. Acromegaly: A unique human headache model. Headache 2003; 43: 794-797.

31. Gravdahl GB, Tronvik EA, Fougner SL, et al. Pituitary adenoma and non-acute headache: Is there an association, and does treatment help? World Neurosurg 2016; 92: 284-291.

32. Freda PU, Beckers AM, Katznelson L, et al. Pituitary incidentaloma: An endocrine society clinical practice guideline. J Clin Endocrinol Metab 2011; 96: 894-904.

33. Oystese KA, Evang JA and Bollerslev J. Non-functioning pituitary adenomas: Growth and aggressiveness. Endocrine 2016; 53: 28-34.

34. Biousse V, D’Anglejan-Chatillon J, Massiou H, et al. Head pain in non-traumatic carotid artery dissection: A series of 65 patients. Cephalalgia 1994; 14: 33-36.

35. Valenca MM, Andrade-Valenca LP, Martins C, et al. Cluster headache and intracranial aneurysm. J Headache Pain 2007; 8: 277-282.

36. Wilbrink LA, Ferrari MD, Kruit MC, et al. Neuroimaging in trigeminal autonomic cephalgias: When, how, and of what? Curr Opin Neurol 2009; 22: 247-253. 